\title{
CORRECTION
}

\section{Correction to: Tribological performance evaluation of fused mullite-reinforced hybrid composite brake pad for defence application}

\author{
V. Vineeth Kumar ${ }^{1} \cdot$ S. Senthil Kumaran ${ }^{2} \cdot$ S. Dhanalakshmi ${ }^{3} \cdot$ R. Sivaramakrishnan ${ }^{4}$
}

Published online: 25 April 2019

(C) The Brazilian Society of Mechanical Sciences and Engineering 2019

\section{Correction to: \\ Journal of the Brazilian Society of Mechanical Sciences and Engineering (2019) 41:179 \\ https://doi.org/10.1007/s40430-019-1682-2}

In the original publication of the article, Fig. 7 has been wrongly overwritten with Fig. 8. The correct Fig. 7 is given below, and the original article has been updated accordingly.
Publisher's Note Springer Nature remains neutral with regard to jurisdictional claims in published maps and institutional affiliations.
Fig. 7 a Fade I performance of HC 1 and $\mathbf{b}$ fade I performance of $\mathrm{HC} 2$ a

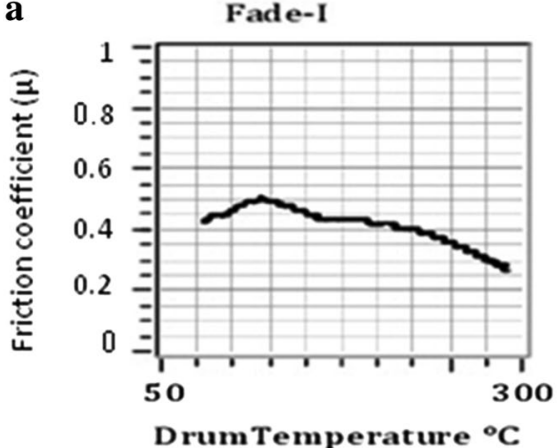

b

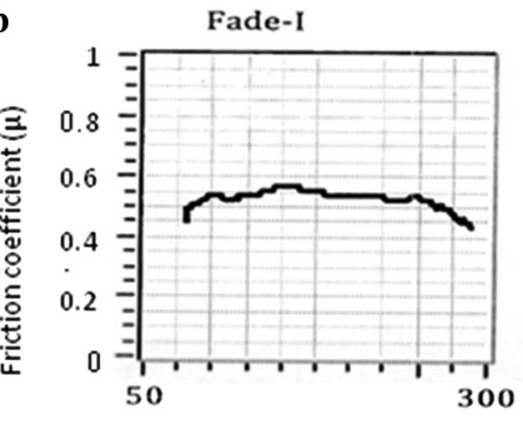

DrumTemperature ${ }^{\circ} \mathrm{C}$

The original article can be found online at https://doi.org/10.1007/ s40430-019-1682-2.

S. Senthil Kumaran

senthilkumaran.s@vit.ac.in

1 School of Mechanical Engineering, Vellore Institute of Technology, VIT, Vellore, Tamilnadu 632014, India

2 Department of Manufacturing Engineering, School of Mechanical Engineering, Vellore Institute of Technology, VIT, Vellore, Tamilnadu 632014, India

3 Combat Vehicle Research and Development Establishment (CVRDE), Chennai 600054, India

4 Department of Production Technology, MIT Campus, Anna University, Chennai 600044, India 